\title{
TU/e EmonOWEN

\section{Theoretical and practical aspects of aroma retention in spray drying and freeze drying}

Citation for published version (APA):

Coumans, W. J., Kerkhof, P. J. A. M., \& Bruin, S. (1994). Theoretical and practical aspects of aroma retention in spray drying and freeze drying. Drying Technology, 12(1-2), 99-149.

https://doi.org/10.1080/07373939408959951

DOI:

10.1080/07373939408959951

Document status and date:

Published: 01/01/1994

\section{Document Version:}

Publisher's PDF, also known as Version of Record (includes final page, issue and volume numbers)

\section{Please check the document version of this publication:}

- A submitted manuscript is the version of the article upon submission and before peer-review. There can be important differences between the submitted version and the official published version of record. People interested in the research are advised to contact the author for the final version of the publication, or visit the $\mathrm{DOI}$ to the publisher's website.

- The final author version and the galley proof are versions of the publication after peer review.

- The final published version features the final layout of the paper including the volume, issue and page numbers.

Link to publication

\section{General rights}

Copyright and moral rights for the publications made accessible in the public portal are retained by the authors and/or other copyright owners and it is a condition of accessing publications that users recognise and abide by the legal requirements associated with these rights.

- Users may download and print one copy of any publication from the public portal for the purpose of private study or research.

- You may not further distribute the material or use it for any profit-making activity or commercial gain

- You may freely distribute the URL identifying the publication in the public portal.

If the publication is distributed under the terms of Article 25fa of the Dutch Copyright Act, indicated by the "Taverne" license above, please follow below link for the End User Agreement:

www.tue.nl/taverne

Take down policy

If you believe that this document breaches copyright please contact us at:

openaccess@tue.nl

providing details and we will investigate your claim. 


\section{THEORETICAL AND PRACTICAL ASPECTS}

OF AROMA RETENTION IN SPRAY DRYING AND FREEZE DRYING

W.Jan Coumans ${ }^{1}$, Piet J.A.M. Kerkhof ${ }^{1}$ and Solke Bruin ${ }^{2}$

${ }^{1}$ Department of Chemical Engineering, Eindhoven University of Technology, P.O.Box 513, 5600 MB Eindhoven, the Netherlands;

${ }^{2}$ Unilever Research Laboratory, P.0.Box 114, 3130 AC vlaardingen, the Netherlands

Key Words and Phrases:

volatiles; trace component; diffusion; selective diffusion; slab drying; dispersed aroma

\section{ABSTRACT}

For many food products the presence of volatile aroma components is a prime quality feature. Upon drying part of these components may be lost, leading to unbalanced flavour patterns in the reconstituted product. The mechanisms of aroma loss in most drying processes are well understood by now. For homogeneously dissolved aroma components this can be described succesfully by Thijssen's selective diffusion theory. Somewhat more complicated is the loss of aroma components which are present in the form of a dispersion.

An extensive overview is given of theory and experimental work on aroma loss in slab drying, spray drying and freeze drying. Practical processing rules following from the basic insights are discussed. It is the intention to present a broad coverage of the subject. 


\section{INTRODUCTION}

The last two decades extensive research has been done on aroma retention in drying, both theoretical and experimental. Both on spray drying and freeze drying large efforts in this field are delivered by the research groups of Thijssen and Kerkhof at Eindhoven University of Technology, the Netherlands) and by King at University of California, Berkeley, USA. On freeze drying substantial contributions are from Karel's group at MIT, Cambridge, USA. The reader is further referred to an extensive literature survey in REFERENCES.

Aroma retention in drying has been studied for several types of drying processes. Studies of major importance are dealing with spray drying and freeze drying (see later). Efforts of minor importance are directed to unconventional and/or "new" drying techniques, like slush drying (Chandrasekaran,1969), extractive drying (Kerkhof and Thijssen, 1974; Kerkhof, 1975), drum drying (Thijssen and Rulkens, 1968) and dual stage drying (Kerkhof, 1975; Kerkhof and Thijssen, 1977). In nearly all cases the experiments were carried out with model systems, consisting of aqueous carbohydrate solutions containing a small amount of a model aroma component (e.g. see Table 1).

This paper is dealing with the theoretical description of aroma retention, considering the mass transfer in the drying material as a ternary diffusion process. To circumvent some practical problems in applying the ternary model, a more practical correlation method will be discussed. The basic insights of the selective diffusion theory will be applied to slab drying, spray drying and freeze drying. Practical 
processing rules, to improve aroma retention in these drying processes, will be discussed.

RELATIVE VOLATILITY AND SELECTIVE DIFFUSION

\section{Relative volatility}

The quality of many liquid foods, like fruit juices, coffee extracts, etc., is mainly determined by the presence of a large number of volatile aroma components. In a dewatering process, consisting of a concentration and/or a drying step, the quality of these products can be affected seriously by thermal degradation of heat sensitive volatiles and by evaporation losses. chemical changes during drying, such as the formation of precursors, and thermal degradation reactions are not considered here. This paper deals with the physical aroma losses due to high relative volatilities.

The relative volatility $\alpha_{\text {iw }}$ of component (i) with respect to water $(w)$ is defined as:

$$
\alpha_{i w}=\frac{y_{i} / x_{i}}{y_{w} / X_{w}}=\frac{\gamma_{i} P_{i}^{0}}{\gamma_{w} P_{w}^{0}}
$$

where $x, y$ are molfractions in liquid and gas phase respectively, $\gamma$ is the thermodynamic activity coefficient $(-/-)$ and $P^{\circ}$ is the saturation vapour pressure $\left(\mathrm{N} / \mathrm{m}^{2}\right)$ of the pure components. Because all the aroma components are present in very low concentrations, the acitivity coefficients in equation (1) have to be taken at infinite dilution $\gamma_{i}=\gamma_{i}^{\infty}$ in the system water-dissolved solids and depend only on water concentration and temperature. In Table 1 the relative volatilities of some typical aroma components are represented. It 
TABLE 1

Relative Volatilities of some Aroma components at Infinite Dilution in water at $100^{\circ} \mathrm{C}$ and their Retentions after Evaporation of $80 \%$ of the Water.

(Bomben et.a1.,1973)

\begin{tabular}{lccl}
\hline aroma component & $\begin{array}{l}\text { Boiling } \\
\text { point } \\
\left({ }^{\circ} \mathrm{C}\right)\end{array}$ & $\begin{array}{l}\text { Relative } \\
\text { volatili- } \\
\text { ty } \alpha_{\text {iw }}\end{array}$ & $\begin{array}{l}\text { Reten- } \\
\text { tion } \\
(\%)\end{array}$ \\
\hline Methyl mercaptan & 5.8 & $>500$ & $10^{-348}$ \\
Acetaldehyde & 20.2 & 210 & $10^{-145}$ \\
Acetone & 56.5 & 46 & $10^{-30}$ \\
Methyl acetate & 57.8 & 113 & $10^{-77}$ \\
Methanol & 64.7 & 8 & $10^{-3.6}$ \\
Ethanol & 78.4 & 12 & $10^{-4.4}$ \\
n-Propanol & 97.8 & 16 & $10^{-9.2}$ \\
Pyridine & 115.4 & 3 & 0.795 \\
n-Butanol & 111.7 & 27 & $10^{-16.9}$ \\
Acetic acid & 118.1 & 0.73 & 31 \\
n-Pentanol & 138 & 32 & $10^{-20.4}$ \\
Methyl anthranilate & 255 & 3.3 & 0.49 \\
\hline
\end{tabular}

should be noticed that in a homologues series, see for example the n-alcohols in Table 1 , a higher boiling point corresponds with a higher relative volatility. Apparently, the lower vapour pressure $P_{i}^{0}$ of the pure aroma component is overcompensated by an increasing activity coefficient $\gamma_{i}$.

In case of equilibrium evaporation of a liquid it can be derived for the aroma retention:

$$
A R=(W R)^{\alpha}
$$

where AR and WR are the fractions of the initial 
amounts of aroma and water respectively, being left at any moment in the evaporation process. In Table 1 the aroma retention is calculated in case of $80 \%$ water removal: From this it can be concluded that in evaporation processes all aroma components are lost nearly completely.

To prevent these catastrophic losses the aroma component can be stripped from the liquid phase by means of water vapour. The aroma rich vapour can be concentrated by distillation under reflux. After the aroma free liquid is concentrated by evaporation, the separate aroma concentrate is rejoined. A better quality preserving method is to concentrate by freeze concentration.

A drying process is essentially a non-equilibrium process and it appears that here the aroma retention is nearly independent on relative volatility. Theoretically it is possible to achieve complete retention of aroma components by taking advantage of the selective diffusion concept, as was first proposed by Thijssen (1965, 1968).

\section{Selective Diffusion}

It is well known that the diffusion coefficients in aqueous solutions are strongly dependent on the water concentration. See for instance the diffusion coefficients of water and aceton in maltodextrin solutions and in (stripped) coffee extract, as represented in Figure 1 (Thijssen and Rulkens, 1968; Menting et al., 1970). In both systems small amounts of aceton were added $(<0.1 \mathrm{wt} \%)$. At decreasing water concentrations there is a strong decrease of the diffusion coefficients both for water and aceton, however the decrease of the aceton diffusion coefficient is much stronger. 


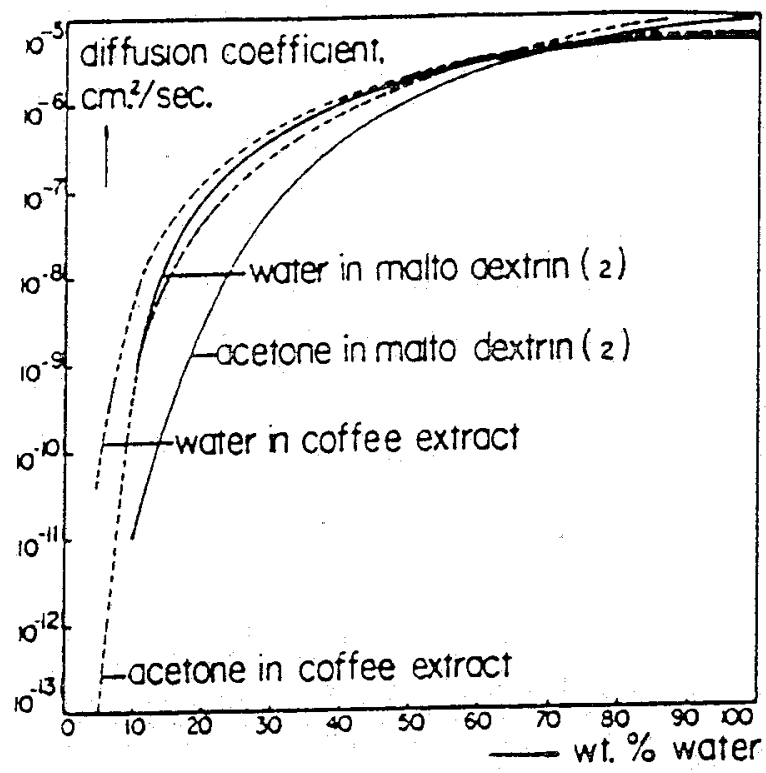

FIGURE 1. Diffusion Coefficients of water and Acetone in coffee extract and aqueous malto dextrin solutions as function of moisture content at $25^{\circ} \mathrm{C}$ (Menting, 1969).

In Figure 2 the ratio of the diffusion coefficients of aceton $\left(D_{a}\right)$ and water $\left(D_{w}\right)$ in coffee extract and aqueous malto dextrin solutions are given. From this it can be concluded that at water concentrations lower than 15 wto the ratio $D_{a} / D_{w}$ becomes so small that the system may be considered impermeable to aceton. Analogous results were found for sugar solutions (Chandrasekaran and $K i n g, 1969,1972$ ). 


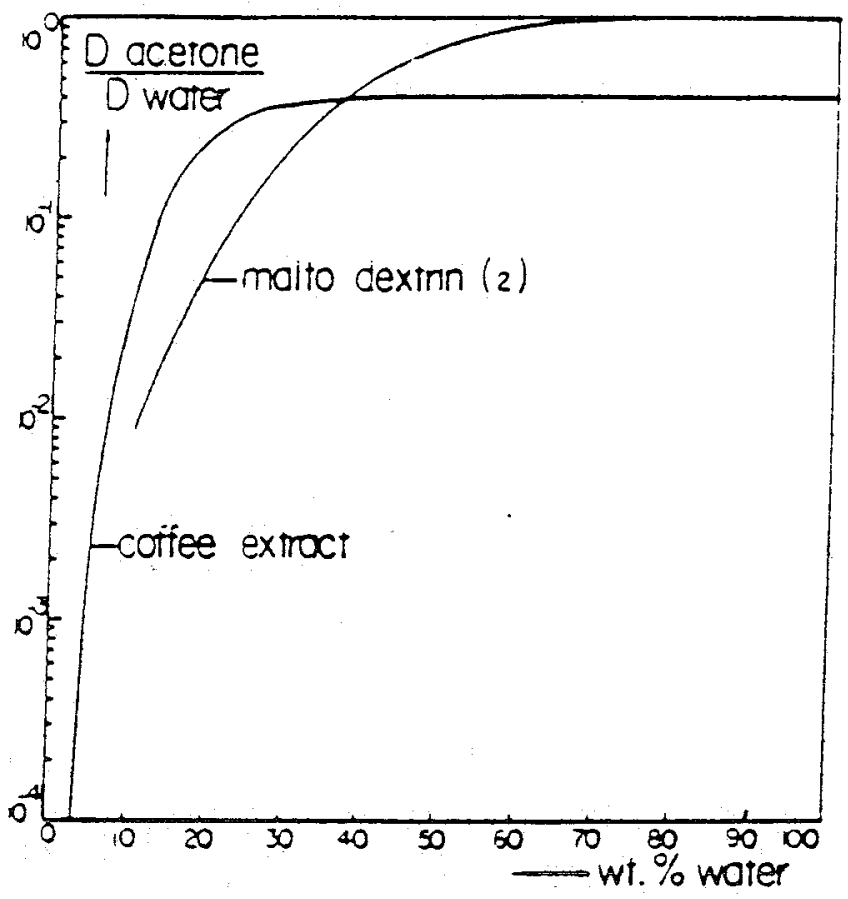

FIGURE 2. Ratio of Diffusion Coefficients of Acetone and water in coffee Extract and Aqueous Malto Dextrin Solution as Function of Moisture content at $25^{\circ} \mathrm{C}$ (Menting, 1969).

In drying processes, like spray drying, there is an internal resistance for mass transfer in the drying material and an external resistance in the surrounding gas phase. At decreasing surface concentrations the internal diffusional transport of water and aceton becomes the controlling and limiting factor in the 
drying proces. At surface water concentrations below 15 wto the interface becomes practically impermeable to volatile aromas. The surface concentration where selective-diffusion comes in action is called the critical concentration. Thus, if the water concentration at the surface is lowered very quickly below the critical value, aroma retentions up to $100 \%$ may be possible.

conclusion: in exploiting the selective diffusion concept for obtaning high aroma retentions, a rapid decrease of the water concentration at the drying interface is a prerequisite. In spray drying and freeze drying favourable conditions for obtaining high aroma retentions can be created.

From all experimental and theoretical investigations it appears that the selective diffusion concept provides an excellent frame work for understanding qualitatively, and in many cases also quantitatively, the effects of product properties and process variables on aroma retention during drying. In spray drying aroma losses occur while the dry skin is being formed. These losses are called diffusional losses. However, additional losses can occur, due to phenomena preventing and/or destroying the retaining action of the selective diffusion mechanism. The effect of all these phenomena, which will be discussed extensively later, can be interpreted in terms of the selective diffusion theory.

\section{TERNARY DIFFUSION APPROACH OF SELECTIVE DIFFUSION}

Obviously the most sound description of mass transfer in multi component systems is given by the Maxwell-stefan approach (Wesselingh and Krishna,1990; Thijssen and Rulkens, 1968; Rulkens, 1973; Kerkhof, 
1975). According to this approach the gradient of the chemical potential is taken now as the driving force (N/mol i) for species i to move:

$$
\text { driving force }=\frac{\partial \mu_{i}}{\partial r}=R T \frac{\partial \ln \left(A_{i}\right)}{\partial T}
$$

where $\mu_{i}$ is chemical potential of $i(\mathrm{~J} / \mathrm{mol}), r$ is space coordinate $(\mathrm{m}), \mathrm{R}$ is gas constant ( $\mathrm{J} / \mathrm{mol} \mathrm{K}$ ), $\mathrm{T}$ is absolute temperature $(K)$ and $A_{i}$ thermodynamic activity of species $i(-/-)$. Due to velocity differences between molecules of different species friction forces are developed. The total friction force (N/mol i) exerted on species $i$ by all other species $j$ is expressed by:

$$
\text { friction force }=\sum_{j=1}^{n} f_{i j} c_{j}\left(v_{j}-v_{i}\right)
$$

where $f_{i j}$ is the so-called binary friction or interaction coefficient $\left(\mathrm{Nm}^{2} \mathrm{~s} / \mathrm{mol}^{2}\right), \mathrm{v}_{i}, \mathrm{v}_{j}$ are velocities $(\mathrm{m} / \mathrm{s})$ and $\mathrm{c}_{j}$ is molar concentration $\left(\mathrm{mol} / \mathrm{m}^{3}\right)$. The driving force on species $i$ is counterbalanced by the friction force on $i$. This leads to:

$$
-c_{i} \frac{\partial \ln \left(A_{i}\right)}{\partial r}=\sum_{j=1}^{n} \frac{x_{j} N_{i}-x_{i} N_{j}}{\tilde{D}_{i j}}
$$

where $x_{i}, x_{j}$ are molar fractions, $N_{i}, N_{j}$ are molar fluxes $\left(\mathrm{mol} / \mathrm{m}^{2} \mathrm{~s}\right), \tilde{\mathbf{D}}_{i j}$ is the binary Maxwell-stefan diffusion coefficient $\left(\mathrm{m}^{2} / \mathrm{s}\right)$, which is related to the binary friction coefficient by:

$$
\tilde{D}_{i j}=\frac{R T}{C} \frac{1}{f_{i j}}
$$

It will be clear that $\tilde{D}_{i j}=\tilde{D}_{j i}$.

In many cases it is more practical to use mass based instead of molar based quantities: 


$$
-\omega_{i} \rho \frac{\partial \ln \left(A_{i}\right)}{\partial I}=\sum_{j=1}^{n} \frac{\omega_{j} n_{i}-\omega_{i} n_{j}}{D_{i j}}
$$

where $\omega_{i}, \omega_{j}$ are mass fractions, $A_{i}$ is thermodynamic activity, $n_{i}, n_{j}$ are mass fluxes $\left(\mathrm{kg} / \mathrm{m}^{2} \mathrm{~s}\right), \rho$ is total mass concentration $\left(\mathrm{kg} / \mathrm{m}^{3}\right), D_{i j}$ is a binary diffusion coefficient $\left(\mathrm{m}^{2} / \mathrm{s}\right)$, which is related to $\tilde{\mathrm{D}}_{\mathrm{ij}}$ by :

$$
D_{i j}=\frac{C}{\rho} M_{j} \tilde{D}_{i j}
$$

and now thus: $M_{i} D_{i j}=M_{j} D_{j i}$, where $M_{i}, M_{j}$ are molecular weights ( $\mathrm{kg} / \mathrm{mol})$.

The activity $A_{i}$ may depend in a very complex way on composition and temperature of the system and it is rather problematic to find sound thermodynamic models for real systems and to dispose of reliable experimental data. To circumvent these problems to a certain extent the driving force is expressed as the gradient of the mass concentration $\rho_{i}$ or mass fraction $\omega_{i}$. Now we will have a look how things work out for mass transfer in liquid foods.

Liquid foods may be considered as pseudo ternary systems (Chandrasekaran, 1969; Rulkens, 1973; Kerkhof, 1975) consisting of water (w), dissolved solids (s) and aroma component (a) as a trace component. From the foregoing it follows that in a ternary system three independent binary diffusion coefficients and two independent mass transfer equations exist.

\section{Mass transfer of water and dissolved solids.}

owing to its very low concentration the aroma component hardly affects the mass transfer of water and dissolved solids, e.g. the friction forces exerted by aroma on water may be neglected with respect to the 
friction force from interaction with dissolved solids. Therefore mass transfer of water and dissolved solids may be treated as a binary mass transfer process, thus from equation (7):

$$
n_{w}=\left(n_{w}+n_{s}\right) \omega_{w}-D_{w} \rho \frac{\partial \omega_{w}}{\partial r}
$$

in which by definition:

$$
D_{w}=D_{w s} \frac{\partial \ln \left(A_{w}\right)}{\partial \ln \left(\omega_{w}\right)}
$$

An analogous equation can be derived for mass transfer of the dissolved solids, however it is more easy to relate $n_{s}$ to $n_{w}$ by making use of the property of equivolumetric mass transfer:

$$
n_{s}=-\frac{d_{s}}{d_{w}} n_{w}
$$

where $a_{s}$, $d_{w}$ are the partial densities of the components $\left(\mathrm{kg} / \mathrm{m}^{3}\right)$. By substituting this equation into equation (9) it can be derived that:

$$
n_{w}=-D_{w} \frac{\partial \rho_{w}}{\partial r}
$$

and if the mass transfer of water is related to the dissolved solids velocity:

$$
j_{w}^{s}=-\frac{D_{w}}{1-\frac{\rho_{w}}{d_{w}}} \frac{\partial \rho_{w}}{\partial r}
$$

where $j_{w}^{s}$ is mass flux in a solids based reference frame. For drying of slabs and spheres the diffusion equation with initial and boundary conditions is given by: 


$$
\begin{array}{lll} 
& \frac{\partial \rho_{w}}{\partial t}=\frac{I}{I^{v}} \frac{\partial\left(-r^{v} n_{w}\right)}{\partial r} \\
t=0 \quad 0 \leq r \leq R_{0} \quad \rho_{w}=\rho_{w 0} \\
t>0 \quad I=0 \quad \frac{\partial \rho_{w}}{\partial I}=0 \\
t>0 \quad r=R(t) \quad j_{w}^{s}=k_{w}\left(\rho_{w i}-\rho_{w+o}\right)
\end{array}
$$

where $\nu=0$ for an infinite extended $s$ lab, $\nu=2$ for $a$ sphere, $k_{w}$ is mass transfer coefficient (m/s) and $\rho_{w i}^{\prime}$ is moisture concentration in gasphase at gasliquid interface $\left(\mathrm{kg} / \mathrm{m}^{3}\right), \rho_{\text {wo }}^{\prime}$ is moisture concentration in bulk gas phase $\left(\mathrm{kg} / \mathrm{m}^{3}\right)$ (see Figure 3 ).

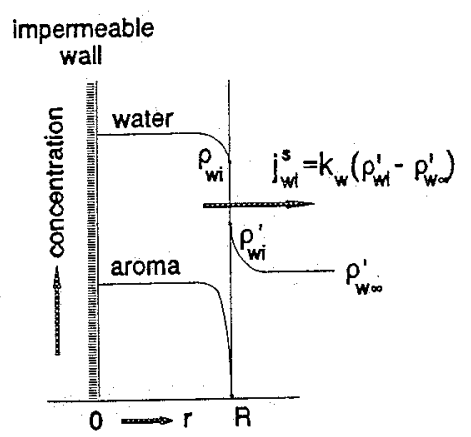

The relation between the $m$ oisture concentrations in both phases at the interface (the water vapour sorption isotherm of the system) has to be known.

FIGURE 3. Schematic representation of interface.

\section{Mass transfer of aroma component}

Because of low concentrations it can be shown (Chandrasekaran, 1971, 1972; Tsujimoto,1982) that similar to Henry's law the aroma activity linearly depends on the aroma concentration, according to $\mathrm{A}_{\mathrm{a}}=\mathrm{H}_{\mathrm{a}} \rho_{\mathrm{a}}$, where $\mathrm{H}_{\mathrm{a}}$ is a modified activity coefficient which depends on the water concentration $\rho_{\mathrm{w}}$ only. By 
using this relationship in modifying the driving force, the following equation for mass transfer of the aroma component can be derived from equation (7):

$$
n_{a}=-D_{a} \frac{\partial \rho_{a}}{\partial I}-D_{a} \rho_{a} \frac{d l n\left(H_{a}\right)}{d \rho_{w}} \frac{\partial \rho_{w}}{\partial r}+\omega_{a} D_{a}\left(\frac{n_{w}}{D_{a w}}+\frac{n_{s}}{D_{a s}}\right)
$$

where by definition:

$$
\frac{1}{D_{a}}=\frac{\omega_{w}}{D_{a w}}+\frac{\left(1-\omega_{w}\right)}{D_{a s}}
$$

and if mass transfer is related to the velocity of the dissolved solids:

$$
j_{a}^{s}=n_{a}+\frac{\rho_{a}}{d_{w}-\rho_{w}} n_{w}
$$

Substitution of the expressions for $n_{w}$ and $n_{s}$ (equations 11 and 12) yields:

$$
n_{a}=-D_{a} \frac{\partial \rho_{a}}{\partial r}-D_{a} \rho_{a}\left[\frac{d \ln \left(H_{a}\right)}{d \rho_{w}}+\frac{D_{w}}{\rho}\left(\frac{1}{D_{a w}}-\frac{d_{s}}{d_{w}} \frac{1}{D_{a s}}\right)\right] \frac{\partial \rho_{w}}{\partial r}
$$

The aroma flux depends both on gradients of $\rho_{a}$ and $\rho_{w}$.

From this it can be concluded that here the Maxwell-stefan description of mass transfer is similar to the approach of thermodynamics of irreversible processes (Chandrasekaran and King, 1972; Kerkhof et.al., 1971; Rulkens, 1973). However the Maxwell-stefan approach provides a better physical insight in what is happening on the molecular level and the diffusion coefficients $D_{w s}, D_{a w}$ and $D_{a s}$ will always show positive values, whereas the transport coefficients from the thermodynamic approach may take on negative values (Kerkhof \& Schoeber, 1974). For instance, it has been shown (Chandrasekaran and King, 1971, 1972) that for 
traces of aroma components in carbohydrate solutions $\left(\mathrm{d} \ln \left(\mathrm{H}_{\mathrm{a}}\right) / \mathrm{d} \rho_{\mathrm{w}}\right)<0$. Moreover, at low moisture concentrations the interactions between dissolved solids and aroma appear to be much stronger than those between water and aroma, thus $\mathrm{D}_{\mathrm{as}}<<\mathrm{D}_{\mathrm{aw}}$. This means that both terms between the brackets in equation (13) may become negative. From this it can be concluded that, at low moisture concentrations, the moisture gradient and the aroma gradient have opposite effects on the aroma transport. Because of this it may happen that the aroma component diffuses against its own concentration gradient, and a maximum in the concentration profile of the aroma component may occur (Chandrasekaran and King, 1971, 1972; Kerkhof, 1975).

The diffusion equation for mass tranfer of aroma component is now given by:

$$
\begin{array}{lll} 
& \frac{\partial \rho_{a}}{\partial t}=\frac{1}{I^{v}} \frac{\partial\left(-I^{v} n_{a}\right)}{\partial I} \\
t=0 \quad 0 \leq I \leq R_{0} \quad & \rho_{a}=\rho_{a} 0 \\
t>0 \quad I=0 \quad & \frac{\partial \rho_{a}}{\partial I}=0 \\
t>0 \quad I=R(t) \quad & j_{a}^{s}=k_{a}\left(\rho_{a}^{\prime}-\rho_{a \infty}^{\prime}\right)
\end{array}
$$

where the last boundary condition $\rho_{\mathrm{a}}=0$ is taken in most cases because the aroma concentration in the drying air is pratically zero and the Biot number for aroma transport is very high (Chandrasekaran and King, 1972; Menting et.al. 1972). In other cases the sorption isotherm of the aroma component has to be known.

\section{overall enthalpy balance in adiabatic drying.}

In adiabatic drying of spheres the above differential equations have to be solved simultaneously with the 
overall enthalpy balance of the sphere:

$$
\rho C_{p} \frac{R}{3} \frac{d \theta}{d t}=\alpha\left(\theta-\theta_{\infty}\right)+j_{w i}^{s} \Delta H_{\text {vap }}
$$

where $\rho$ is total mass concentration of sphere $\left(\mathrm{kg} / \mathrm{m}^{3}\right)$, $c_{p}$ is specific heat $\left(\mathrm{J} / \mathrm{kg}{ }^{\circ} \mathrm{C}\right), \alpha$ is heat transfer coefficient $\left(\mathrm{W} / \mathrm{m}^{2 \circ} \mathrm{C}\right), \theta$ is temperature $\left({ }^{\circ} \mathrm{C}\right)$ of drying sphere (for small spheres the Biot number for heat transport is close to zero so that temperature profile in the sphere is flat $\left.\theta=\theta_{i}\right), \theta_{\infty}$ is temperature $\left({ }^{\circ} \mathrm{C}\right)$ of the bulk gas phase, $\Delta \mathrm{H}_{\mathrm{vap}}$ is evaporation enthalpy of wa$\operatorname{ter}(J / \mathrm{kg})$.

\section{Computer simulations}

The main physical properties needed in the above differential equations are the diffusion coefficients and the sorption isotherms of water and aroma component. For a short review of available properties the reader is referred to literature (Chandrasekaran, 1969; Kerkhof and Schoeber, 1974; Tsujimoto, 1985).

A typical result of a computer simulation is represented in Figure 4. The drying history of a rigid droplet of a maltose solutions is simulated (initial moisture content is $45 \mathrm{wt} \%$, air temperature is $100{ }^{\circ} \mathrm{C}$ and air humidity is $0.03 \mathrm{~kg} / \mathrm{kg}$ ). The temperature, the fractional water content and the fractional aroma content (= aroma retention) of the droplet are given as function of the reduced time $t / R_{0}{ }^{2}$. Only the first part of the drying history, during which the aroma loss takes place, is considered. In the beginning of the drying process the droplet temperature rises to the wet bulb temperature $\left(42{ }^{\circ} \mathrm{C}\right)$, then remains nearly constant for a while and at $t / R_{0}{ }^{2} \approx 0.5 \times 10^{8}$ the temperature starts to increase again. It should be noticed that at that time also the aroma retention levels off to a con- 


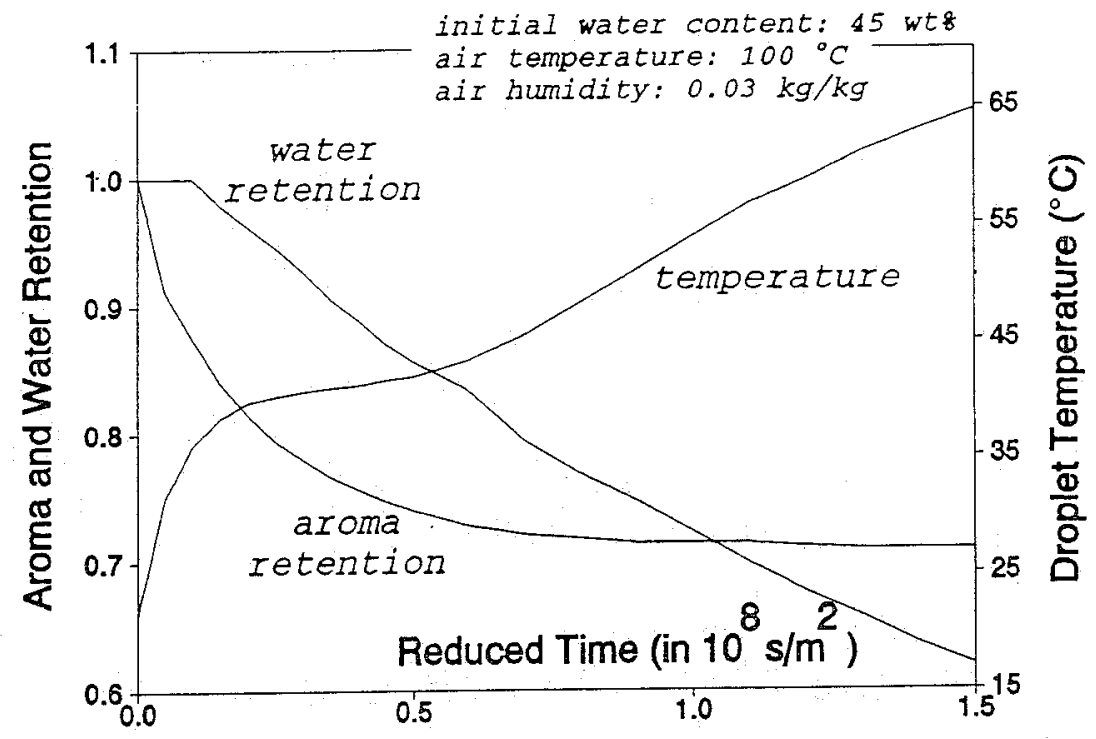

FIGURE 4. Calculated temperature, water retention and aroma retention for rigid droplets of aqueous maltose solution as function of reduced time $\left(t / R_{0}{ }^{2}\right)$ (Kerkhof and Schoeber, 1974)

stant value, whereas the losses of water still continue. Apparently, the semi-permeable skin has been formed and the drying process continues without further aroma losses.

\section{BINARY DIFFUSION APPROACH AND CORRELATION METHOD}

From a practical point of view the ternary diffusion approach has some serious drawbacks. The numerical solution of the above (partial) differential equations is a rather heavy task. But more serious is the lack of 
reliable physical data on diffusion coefficients $D_{a w}$, $D_{a s}, D_{w s}$, activity coefficients $\gamma_{i}$ of aroma components in solutions and equilibrium data for aroma component and water. The experimental determination of the above mentioned physical properties requires sophisticated methods, a well equipped laboratory, well skilled researchers and a lot of time. Still today there is an urgent need for improvement of the experimental methods.

By analysing computer simulations, based on the ternary diffusion approach, an approximate method for the calculation of aroma retention during drying has been developed (Kerkhof, 1974, 1975; Kerkhof and Thijssen, 1977). This method is based on the observation that most of the aroma is lost during the first drying period (nearly constant wateractivity at the surface). The physical data needed now are the water vapour sorption isotherm, the partial densities of water and dissolved solids and some diffusion parameters, which can be derived in a simple way from slab drying experiments.

\section{Constant Activity Period and critical Time}

For constant conditions of the drying air the drying flux of a slab during this period will be constant, thus $j_{w i}=j_{w i o} ;$ assuming $s h=2$ the drying flux of a sphere is related to its radius by $j_{w i} R=j_{w i o} R_{0}$. This drying period ends if the water activity at the surface has reached a critical value (e.g. $\left.A_{w i}=0.9\right)$, the critical surface water concentration is then given by $\rho_{\text {wc }}$ and the averaged concentration by $\bar{\rho}_{w C}$; the duration of this period is given by $t_{c}$ and the radius or half thickness of the system by $R_{c}$.

From a similarity analysis of the diffusion equation 
for water transport a functional relationship between the following parameters should exist:

$$
\begin{array}{cl}
\Phi_{c} & =\frac{t_{c}}{R_{0}^{2}} \quad \text { reduced critical time } \\
\epsilon & =\frac{j_{w i o}^{s} R_{0}}{d_{w}} \quad \text { reduced flux }
\end{array}
$$

Let us consider two extreme situations:

- At extremely high intitial drying fluxes the surface concentration will reach the critical value while the concentration profiles are not yet penetrated to the center of the material. Both slab and sphere behave as semi infinite bodies; because the penetration depth will be very small with respect to the radius, the sphere behaves as a slab. By analysing the computer simulations it can be shown that:

$$
\phi_{c}=\frac{F_{w}}{\epsilon^{2}}
$$

in which $F_{w}$ is a factor $\left(\mathrm{m}^{2} / \mathrm{s}\right)$, depending on $\rho_{\text {wo }}$ and $\rho_{\mathrm{wc}}$ and the concentration dependence of the diffusion coefficient. Based on computer simulations, the following correlation could be formulated:

$$
F_{\mathrm{w}}=F_{\mathrm{w} O} \exp \left(-\frac{E_{\mathrm{w}}}{R T}+f_{\mathrm{w}} \frac{\rho_{\mathrm{wO}}}{d_{w}}\right)
$$

where $F_{w o}\left(m^{2} s\right), E_{w}(J / m o l)$ and $f_{w}(-/-)$ are correlation parameters. It should be recognized that for semi infinite bodies $t_{c}$ is independent on the thickness $R_{0}$ of the system.

- At extremely low drying fluxes the water concentration profiles in the material will be nearly flat. If the volume change of the system equals the volume of the removed water, both for slab and sphere it holds: 


$$
\begin{aligned}
& \frac{d R}{d t}=-\frac{j_{w i}^{s}}{d w} \\
& t=0 \quad R=R_{0} \\
& t=t_{c} \quad R=R_{c}
\end{aligned}
$$

from which by integration:

$$
\phi_{C}=\frac{B_{\nu}}{\epsilon} \quad \text { with } \quad B_{\nu}=\frac{2}{\nu+2}\left[1-\left(\frac{R_{c}}{R_{0}}\right)^{\frac{\nu+2}{2}}\right]
$$

Because the concentration profiles are flat a mass balance of the dissolved solids gives:

$$
\frac{R_{c}}{R_{0}}=\left[\frac{d_{w}-\rho_{w O}}{d_{w}-\rho_{w C}}\right]^{\frac{1}{v+1}}
$$

and the constant $B_{\nu}$ becomes:

$$
B_{v}=\frac{2}{v+2}\left[1-\left(\frac{d_{w}-\rho_{w 0}}{d_{w}-\rho_{w C}}\right)^{\frac{v+2}{2(v+1)}}\right]
$$

It is interesting to note that the critical time is inversely proportional with the water flux, where the factor $B_{\nu}$ depends on geometry, the initial and the critical water concentration.

- The intersection point of the two approximate solutions is given by:

$$
\epsilon_{i s}=\frac{F_{w}}{B_{v}} \text { and } \phi_{c, i s}=\frac{B_{v}{ }^{2}}{F_{w}}
$$

Some more sophisticated short cut methods for the calculation of drying histories are available in literature (Schoeber, 1976; Liou, 1982; Coumans, 1987). 


\section{Aroma Loss and Effective Aroma Diffusion Coefficient}

The following assumptions are made: aroma losses occur only during the constant activity period, mass transfer of aroma component can be described by a constant (effective) binary diffusion coefficient $D_{a, e f}$ during this period, for water concentrations below the critical value the aroma diffusion coefficient becomes zero, the slab or sphere are non shrinking and thus have a constant dimension $R_{0}$. Because of the extremely high initial volatility the interfacial aroma concentration is taken zero. For the diffusion equation with these type of conditions analytical solutions can be found in literature (Crank, 1975; Luikov, 1968; Carslaw and Jaeger, 1959). Approximations for the aroma retention (AR) valid for short times and long times are given by:

$$
A R=1-2(v+1)\left(\frac{F O_{c}}{\pi^{2}}\right)^{\frac{1}{2}} \quad F O_{c}<(0.22-0.1 v)
$$

and

$$
A R=\frac{8-v}{\pi^{2}} \exp \left(-\frac{\pi^{2} F O_{c}}{4-\frac{3}{2} v}\right) \quad F O_{c} \geq(0.22-0.1 v)
$$

where the critical Fourier number $\mathrm{FO}_{\mathrm{c}}=\mathrm{D}_{\mathrm{a}, \text { eff }} \phi_{c}$. The transition of the short time and long time approximations lays at $\mathrm{AR}=0.5$.

From slab drying experiments and computer simulations it was found that $D_{a, e f f}$ could be correlated with initial moisture content and temperature according to:

$$
D_{a, \text { eff }}=D_{a o} \exp \left(-\frac{E_{a}}{R T}+f_{a} \frac{\rho_{w o}}{d_{w}}\right)
$$

where $D_{a o}, E_{a}$ and $f_{a}$ are correlation parameters. 
TABLE 2

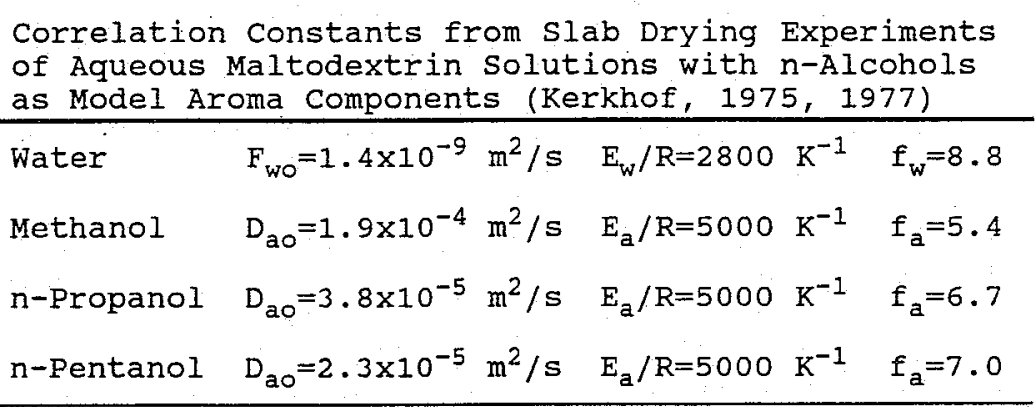

\section{Prediction of Aroma Retention.}

By measuring the critical time and the aroma retention during the drying of slabs the correlation parameters in equations (23) and (31) can be determined. In principle at least three slab drying experiments performed at two temperature and two concentration levels are needed. Regarding the experimental procedures the reader is referred to literature (Menting, 1969, 1970; Rulkens, 1973; Kerkhof, 1975). Once the correlation constants are known (e.g. Table 2) the prediction of aroma retention for a given drying process is straightforward and simple. Firstly $D_{a, e f f}, F_{W}$, $B_{\text {nu, }} \epsilon_{\text {is }}$ and $\epsilon$ are calculated, if $\epsilon>\epsilon_{\text {is }}$ then $\phi_{c}$ is calculated from equation (22) else. $\phi_{c}$ is calculated from equation (25). Next $F_{c}$ follows from $D_{a, \text { eff }}$ and $\phi_{c}$ and finally the aroma retention can be found with equation (29) or (30).

Despite the binary approach the correlation method contains the main characteristics of selective diffusion and enables a rough estimate of the effect of product properties and process parameters on the aroma retention. 


\section{SLAB DRYING}

comparison of predictions from the correlation method and observations from isothermal slab drying experiments with model systems shows a reasonable agreement (Kerkhof, 1974, 1975). Drying of slabs is most suitable for a fundamental study of the factors influencing selective diffusion (Menting, 1969; Chandrasekaran, 1969; Rulkens, 1973; Kerkhof, 1974, 1975; coumans, 1991). Process conditions can be controlled extremely well (e.g. isothermal and uniform temperatures of drying slab) and the cccurence of additional losses can be minimized or even avoided. In Figure 6 unsmoothed data are given from a very accurate experimental set up for slab drying (Coumans, 1991). Aroma losses and water losses are measured continuously during the drying of a slab in a drying chamber with an ideally mixed gas phase. In this example the experimental conditions are: 30 wt\% dissolved solids, slab temperature is $30^{\circ} \mathrm{C}$, slab thickness is $2.5 \mathrm{~mm}$, mass transfer coefficient for water in gas phase is 0.05 $\mathrm{m} / \mathrm{s})$.

Figure 5 clearly shows that the aroma loss tends to a limiting value, whereas the water loss still continues to increase. Though samples and conditions are different, there is qualitatively a good agreement with the calculated observations in Figure 4 .

Drying conditions leading to a rapid formation of a dry semi permeable skin at the external surface of the drying material will promote the retention of aroma components. Both theory and experiment show that in isothermal drying of gelled slabs aroma retention increases with:

- increasing initial concentration of dissolved solids;

- increasing initial thickness of slab; 


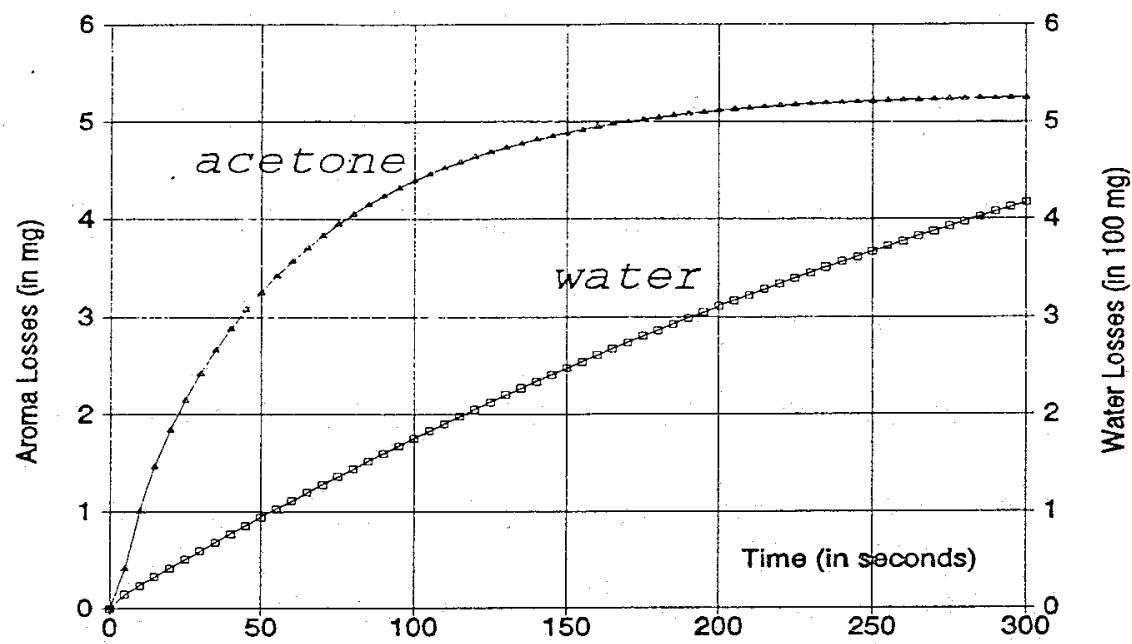

FIGURE 5. Accumulated losses of water and acetone during isothermal drying of thin slab of aqueous malto dextrin solution. (Coumans, 1991).

- decreasing the relative humidity of drying air;

- increasing mass transfer coefficient in gas phase;

- increasing temperature of slab.

Unfortunately, in most cases liquid foods are dried in spray dryers, because higher specific surface areas can be created. Now, some additional phenomena come into play thereby disturbing the above processing rules.

SPRAY DRYING

Mechanisms for Aroma Losses

Several review papers are available on spray drying (Kerkhof and schoeber, 1974; Kerkhof and Thijssen, 1975). An excellent introduction to aroma retenti- 
on in spray drying has been published recently (King, 1990).

The experimentally observed aroma retention in conventional spray drying processes appears to be significantly lower than expected from the selective diffusion theory. In a spray drying process several mechanisms for aroma losses can be distinguished (King, 1990):

- Losses in the cone sheet from the (pressure) nozzel prior to droplet formation. In the very thin cone sheet the liquid is highly turbulent, and a dry semi permeable skin can not be built up. The amount of aroma losses depends on the length and velocity of the sheet and of the relative volatility of the aroma component. - Losses in the freshly formed droplets because of internal circulations, oscillations of droplets, all preventing the formation of a dry skin.

- Losses in the nozzle zone due to a bad mixing condition of the dense spray and the drying air. In this region a great deal of the evaporation takes place in a dense swarm of droplets causing unfavourable local conditions of the air, viz. low temperature and high humidity.

- No losses if internal circulations and oscillations are smoothed, the droplets behave as stagnant spheres and the selective diffusion concept comes to full expression.

- Losses due to morphological changes of the particles. once a dry skin has been formed the droplet temperature starts to increase from the wet bulb to the air temperature. At high droplet temperatures vapour bubbles may be formed, causing expansion of the droplet. Also possible air bubbles incorporated in the droplets during the atomisation process will lead to droplet inflation. The balloonlike expansion of droplets re- 
sults in surface renewal (specific area increases), smaller diffusion distances from the innerside to the surface. At high expansions the formation of cracks and craters. in the dry skin may occur, leading to puffing and aroma components are no longer protected by a well closed selective membrane.

\section{single Droplets}

Drying of single droplets, essentially a nonisotherm drying proces, provides information on both diffusional and additional losses due to morphological changes during drying (Furuta et al., 1984, 1985; Tsujimoto, 1985; verderber and King, 1991). By making use of a video camera and by a continuous detection of the aroma losses the effect of morphological changes of the droplet on the aroma losses can be observed directIy (Verderber and king, 1991)。

\section{Swarm of Droplets in spray Dryer}

The contribution of the above mentioned mechanisms of aroma losses are experimentally determined by taking samples at different heights in a laboratory spray drier (King, 1990; Tsujimoto, 1985). From this experimental observations and by applying the concept of selective diffusion processing rules can be derived. Unfortunately, most factors promoting selective diffusion also promote mechanisms for additional aroma losses and proces conditions have to be optimized. So far no quantitative rules are available to deal with all aspects of aroma retention in spray drying.

\section{Processing Rules in spray Drying}

The selective diffusion concept provides an excellent frame work for understanding aroma losses in spray drying. Deriving processing rules for obtaining high 
aroma retentions in spray drying are directed to the promotion of the selective diffusion concept thereby reducing the additional losses mentioned above.

The influence of several process variables will be discussed now.

1. Increasing the inlet air temperature. Provided a cocurrent drying processes and a well mixing of inlet air with the spray, a higher inlet air temperature imposes higher initial drying rates and steeper concentration gradients and therefore higher aroma retentions may be expected. However, at high air temperatures (e.g. over $200^{\circ} \mathrm{C}$ ) this positive effect may be complety overruled by additional losses due to expansion of droplets as explained before. The net result of increasing air inlet temperature may be a disastrous drop of aroma retention and an undesired low bulk density. The effect of mixing and flow patterns in a cocurrent spray drier on aroma retention will be discussed later.

2. Increasing the dissolved solids concentration in the feed. This is one of the most powerful process parameters to achieve a markedly improvement of aroma retention. However, there are restrictions because of opposing effects. A higher solids concentration leads to a higher viscosity of the feed, which has some consequences for the atomisation process.

Firstly, the length of the high turbulent cone sheet will increase, this promotes aroma losses in the nozzle zone. However also water losses of the sheet are promoted which is favourable for the selective diffusion process in the stagnant spheres. It has been shown (King, 1990) that for coffee extract solutions with 30 and 40 wt\% solids most of the aroma losses occurs in the cone sheet; for 15 wt\% solutions there is nearly a 
total loss of aroma components, mainly because of the delayed onset of selective diffusion.

secondly, high viscosity feeds will produce larger droplet.sizes. The influence of droplet size on aroma retention is less pronounced because, the positive effect of a smaller specific surface area is cancelled by a reduced mass transfer coefficient in the gas phase. It can easily be seen from equations (29) and (30) that for the limiting case of $\mathrm{sh}=2$ the aroma retention is independent on droplet size. If $S h \sim R e^{1 / 2}$ then larger drops will lead to an improvement of aroma retention.

3. Increasing the feed temperature. A prerequisite for high feed concentrations is that the viscosity remains low enough for proper atomisation. This means that high retentions are obtained for combinations of high feed concentrations and high feed temperatures. A high feed temperature also causes higher initial droplet temperatures and the resulting higher initial drying flux will cause an earlier onset of selective diffusion.

4. Addition of thickners like carboxy methyl cellulose or gums to the feed (Thijssen and Rulkens, 1968) suppress the internal circulations and oscillations of droplets and will put the selective diffusion into action earlier. It was experimentally found, that addition of gelatin (1, wt\%) to maltodextrin solutions reduced the aroma losses (acetone) in the nozzle zone markedly, while total drying time was hardly affected (Tsujimoto, 1985).

5. Foaming the feed by admixing a gas causes the cone sheet to break up sooner by a perforation mechanism (Frey and King, 1986). This results in lower sheet losses. However, the more open structure of the droplets may give rise to expansion and additional aroma losses. Foaming the feed by desorption of a supersatu- 
rated solution of e.g. carbon dioxide does not produce higher aroma retention, because the formation of gas bubbles occurs to slowly for playing a role in sheet break up.

6. Addition of an oil phase to the feed. By emulsifying an extractive oil phase to the feed the concentration of the aroma components in the continuous phase decreases. Moreover, the dispersed oil phase promotes the perforation mechanism for breaking up of the cone film. Both effects will improve aroma retention (Zakarian and King, 1982). However, the olfactory response of the reconstituted product may also be reduced by the extractive oil phase.

7. Atomisation at higher pressure. This results in a reduced sheet length and higher sheet velocities. Therefore the exposure time of the sheet to the drying air becomes shorter and aroma retention is improved. Moreover, by exchange of momentum from the spray to the air an improved mixing effect may be expected, whereby in cocurrent drying hot and dry inlet air is drawn into the spray. However, at a too high atomisation pressure the "pumping" of the air by the spray influences the overall flow pattern within the drier in an unfavourable way: back mixing of cooler and more humid air occurs, thereby reducing the driving forces for the initial drying rates of the droplets and the onset of selective diffusion is delayed (King, 1990). From this reasoning an optimal atomizer pressure will exist for a maximal aroma retention. Moreover the atomiser pressure influences the mixing and flow pattern in the spray drier and subsequently also the particle trajectories. Interesting details are reported by king (1990).

8. Type of atomiser. It was suggested by Thijssen (1970) that higher aroma retentions might be expected by using an atomising device, e.g. a centrifugal disk, 
that does not produce a high droplet density near the atomiser, but produces drops from a relatively large disk diameter perpendicular to the air stream. So far there is no experimental evidence for this reasoning. 9. Double stage spray drying. Detrimental effects of particle expansion can be excluded by spray drying at high air temperatures in order to create quickly a dry skin and next after drying at lower air temperatures in e.g. a fluid bed drier or moving belt drier (Kerkhof, 1975; Thijssen and Kerkhof, 1977). Additionally, less chemical and enzymatic damage will occur and bulk density will not drop to unacceptable values. The positive effect of double stage spray drying on aroma retention was confirmed experimentally.

\section{FREEZE DRYING}

Also in freeze drying high aroma retentions are attainable. Because of the low processing temperatures thermal degration reactions are excluded. Moreover, a porous product is formed with excellent rehydration properties. Generally, freeze dried foods have a better quality than spray dried foods.

A freeze drying process is inherently a two stages process: freezing of the material and subsequently drying by sublimation of the formed ice. In understanding the freeze drying process and the retention of aroma components both stages have to be considered.

\section{Freezing Process}

Upon freezing aqueous solutions ice crystals are formed, thereby leaving a concentrated matrix phase. The water concentration in the liquid matrix phase depends on temperature. At decreasing temperatures down 
to the point of vitrification the water concentration decreases. At reaching the vitreous state, where the matrix becomes an amorphous solid, the water concentration remains constant and ice crystals are no longer formed. As an example, for glucose/fructose solutions containing 25 wt\% dissolved solids $(3 \mathrm{~kg}$ water/kg dry solids), the experimentally observed relation between temperature and dissolved solids concentration is given in Figure 6 . From this freezing curve, it can be seen that cooling to $-20^{\circ} \mathrm{C}$ leads to a concentrate with 63 wt\% dissolved solids $(0.59 \mathrm{~kg}$ water $/ \mathrm{kg}$ dry solids), thus 80 wt\% of the water has been segregated as ice.

At unidirectional freezing, like the freezing of a slab on a cooled tray, the ice crystals grow perpendicularly to the cooled surface and form continuous connections from one side of the slab to the other. The geometry of the ice crystals can vary between a more or less straight cylindrical form to a tortuous cellular form. The frozen material shows a honeycomb-like structure. Typical sizes of the

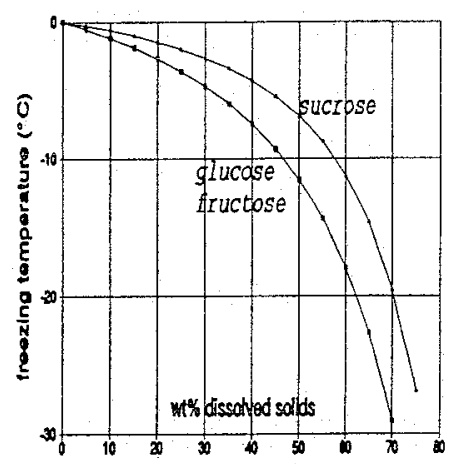

FIGURE 6. Freezing curves aqueous solutions of glucose, fructose and sucrose. (Chandrasekaran, 1969) ice crystals can range from $1-100 \mu \mathrm{m}$. The mean diameter and geometry of the ice crystals depend on freezing rate, initial dissolved solids concentration and type of dissolved solids. At higher freezing rates smaller ice crystals are formed. At increasing initial dissolved solids concentration 
smaller ice crystals are formed in the lower concentration range, whereas in the higher concentration range the size of the crystals becomes more or less independent on the solids concentration.

If freezing occurs slowly the ice crystals are pure and the aroma components are concentrated in the matrix phase. It can be expected that part of the aroma components are permanently encapsulated by dissolved solids; at very high freezing rates also encapsulation in the ice crystals may occur.

\section{Drying Process and selective Diffusion}

In drying the majority of water in the frozen material is removed by sublimation of the ice crystals. upon sublimation the ice crystals are leaving open pores in the material and the sublimation front (or ice front) is retreating into the material. The water in the matrix phase evaporates at the pore walls, subsequently diffuses through the open pores to the surface of the material, and is removed from the surface by mass transfer in the drying chamber. The aroma components in the matrix phase can only escape by evaporation at and above the sublimation front, because of the complete impermeability of the ice crystals. The loss of water and aroma components from the matrix phase into the open pores is governed by a ternary diffusion process as formerly explained. Because of the concentration dependences of diffusion coefficients the retention of aroma components can be understood by the selective diffusion mechanism in the matrix phase. Generally, near the sublimation front the temperature is lower than $-20^{\circ} \mathrm{C}$ and the water concentration in the matrix phase is below 35 wt\% (e.g. see Figure 6). These conditions are very favourable for selective diffusion and high aroma retentions should be possible. 
At low temperatures the driving forces for drying are small and therefore freeze drying is carried out in vacuum chambers. In slab drying the sublimation heat is transferred to the sublimation front either via the frozen part (bottom) or via the dried part (top). In many cases, liquid foods are granulated after freezing and subsequently a layer of granules is dried in a batch tray freeze dryer. Also, continuous freeze dryers have been developed.

\section{Drying Time}

The modelling of the freeze drying process is extremely difficult for several reasons: the diffusion process is 3-dimensional in a non-symmetrical system, the ice crystals have irregular shapes and their sizes may differ considerably, the strong dependence of the diffusion coefficients for water and aroma on concentration and temperature, the boundary condition depends on the location of the sublimation front, etc. However, to provide a basic insight in the influence of process and product properties on the aroma retention, a simplified approach will be discussed.

A schematic representation of a simplified freeze drying process of a slab is given in Figure 7. The following assumptions are made:

- The ice crystal are uniform in size and shape and will be considered as cylinders with diameter $d_{p}$, which will leave open pores with the same shape and diameter. - The ice crystals are uniformly distributed in the matrix phase and the average thickness of the interstitial walls is $2 \delta$.

- The ice front is uniformly retreating over the whole slab. This Uniformly Retreating Ice Front (URIF) model (Sandall et al., 1967; Sandall, 1968) appears to be of practicable value (King, 1971; Karel,1973). 


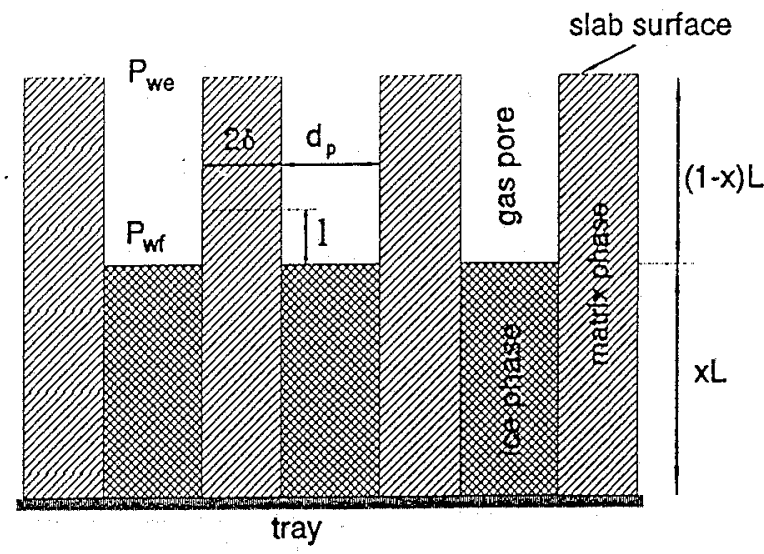

FIGURE 7. Schematic representation of a freeze-drying slab.

In case heat is supplied through the dry part, the heat flux to the ice front is given by:

$$
q=\lambda_{d} \frac{\left(\theta_{e}-\theta_{f}\right)}{(1-x) L}
$$

in which $q$ is heat $f$ Iux $\left(J / \mathrm{m}^{2} \mathrm{~s}\right), \lambda_{\mathrm{d}}$ is thermal conductivity of dry part $(\mathrm{W} / \mathrm{m} \mathrm{K}), \theta_{\mathrm{e}}$ is temperature at slab surface $\left({ }^{\circ} \mathrm{C}\right), \theta_{f}$ is temperature at ice front $\left({ }^{\circ} \mathrm{C}\right)$, I is thickness of slab (m) and $x$ is relative height of ice front.

For heat transfer through the frozen part:

$$
q=\lambda_{f} \frac{\theta_{p}-\theta_{f}}{x L}
$$

with $\lambda_{f}$ is thermal conductivity of the frozen part $\left(\mathrm{W} / \mathrm{m}^{\circ} \mathrm{C}\right)$ and $\theta_{\mathrm{p}}$ is tray temperature $\left({ }^{\circ} \mathrm{C}\right)$.

At normal freeze drying conditions the maximum pressure is less than $150 \mathrm{~Pa}$ and maximum pore sizes are $100 \mu \mathrm{m}$. 
This means that the vapour flow in the pores is mainly by Knudsen diffusion. Thus the rate of ice sublimation is given by:

$$
n_{w}=€ D_{K} \frac{M_{w}}{R T} \frac{P_{w f}-P_{w e}}{(1-X) L}
$$

where, $\epsilon$ is volume fraction of ice $(-/-), D_{K}$ is Knudsen diffusion coefficient $\left(\mathrm{m}^{2} / \mathrm{s}\right), \mathbb{M}_{\mathrm{w}}$ is molecular mass of water $(\mathrm{kg} / \mathrm{mol}), R$ is gas constant ( $\mathrm{J} / \mathrm{mol} \mathrm{K}), \mathrm{T}$ is absolute temperature (K), $P_{w f}$ is vapour pressure at ice front $(\mathrm{Pa}), \mathrm{P}_{\text {we }}$ is vapour pressure at slab surface (Pa). The Knudsen diffusion coefficient is related to pore diameter and temperature according to:

$$
D_{K}=\frac{2}{3} d_{p}\left(\frac{2 R T}{\pi M_{w}}\right)^{\frac{1}{2}}
$$

The equilibrium vapour pressure at the ice front can be described by the Clausius-clapeyron equation (Rulkens, 1973) :

$$
\ln \left(P_{W}\right)=28.900-\frac{6138}{T}
$$

From a mass balance for water over the drying slab:

$$
n_{\mathrm{w}}=-\epsilon d_{i c e} \frac{d(x L)}{d t}
$$

in which $d_{\text {ice }}$ is density of ice $\left(\mathrm{kg} / \mathrm{m}^{3}\right)$.

Assuming that all supplied heat is used for sublimation of ice, the enthalpy balance reads:

$$
q=n_{w} \cdot \Delta H_{s}
$$

where $\Delta \mathrm{H}_{\mathrm{s}}$ is specific heat of sublimation $(\mathrm{J} / \mathrm{kg})$.

For not too large temperature differences the clausiusclapeyron equation can be linearized and the above equations can be solved analytically (Rulkens, 1973). 
The following expressions can be derived for the total drying time:

$$
\tau=\frac{\alpha L^{2}}{D_{K}}\left(I+\beta D_{K}\right)
$$

in which

$$
\alpha=\frac{1}{2} d_{i c e} \frac{R T_{f}}{M_{w}} \frac{1}{P_{w f}-P_{w e}}
$$

if heat transfer through dry part then $\beta=0$

and if heat transfer through frozen part then:

$$
\boldsymbol{\beta}=\boldsymbol{\epsilon} \frac{M_{w}{ }^{2} \Delta H_{s}{ }^{2} P_{w f}}{R^{2} T_{f}{ }^{3} \lambda_{i c e}}
$$

\section{Aroma Retention and Fourier time}

Because of a high vapour diffusivity and a small pore diameter there is virtually no vapour pressure gradient in the radial direction of the pores. Thus, at any position in the longitudinal direction, the interfacial moisture concentration in the matrix phase is in equilibrium with the local vapour pressure. The vapour pressure, and thus also the interfacial moisture concentration, decreases from the ice front to the external slab surface. At a distance $I$ above the ice front the critical moisture content is reached and thus at distances $\geq I$ the matrix surface has become impermeable for aroma components (see Figure 7). The rate at which the aroma diffusion coefficient decreases depends on the rate of the decrease of the local vapour pressure, and thus depends on the sublimation rate. Thus at any height in the slab, the time during which aroma components are lost, is linked to the total drying time $\tau$. Further, the rate of aroma transport will depend on the half thickness $\delta$ of the pore wall and the initial value 
of the aroma diffusion coefficient $D_{a o}$. Eventually, it may be concluded that aroma retention will be coupled quantitatively to a Fourier number (Kerkhof, 1975):

$$
F O=\frac{D_{a o^{\tau}}}{\delta^{2}}
$$

and aroma retention will increase with decreasing Fourier number. Substitution of equation (39) into equation (42) gives:

$$
F O=\alpha \frac{D_{a O}}{D_{K}} \frac{L^{2}}{\delta^{2}}\left(1+\beta D_{K}\right)
$$

\section{Processing Rules for slabs}

In order obtain high aroma retentions one should strive for low values of the Fourier number. Equation (43) forms a good criterium, to understand the effect of process and product properties on the aroma retention. Several processing rules will now be discussed.

1. At lower freezing rates the formed ice crystals will be larger and thus the mean diameter $d_{p}$ of the pores increases. This means that the resistance for mass and heat transfer in the dry part decreases (the Knudsen diffusion coefficient $D_{K}$ increases). Further, the wall thickness $\delta$ will increase because the number of ice crystals decreases. The parameters $\alpha$ and $\beta$ are not directly affected by the freezing rate. From this reasoning the Fourier number decreases and aroma retention is improved (Figure 8). An additional improvement may be expected from a lower moisture concentration in the matrix phase and the corresponding lower value for $\mathrm{D}_{\mathrm{ao}}$ :

2. Increasing the initial dissolved solids concentration reduces the volume fraction of ice and thus decreases the porosity $\epsilon$; the interstitial wall thickness $\delta$ 
increases at approximately constant pore diameters. This leads to an increase of the aroma retention.

3. A decrease in temperature $T_{f}$ at the ice front increases $\alpha$ and decreases $\beta$ (if $\beta \neq 0$ ), $D_{K}$ and $D_{a o}$. If $D_{a o}$ would be constant then the Fourier number would increase considerably and aroma retention would decrease strongly. However, the effect of temperature on $D_{a o}$ is twofold: firstIy, at a constant moisture concentration the $D_{\text {ao }}$ decreases, however this effect is of minor importance here; se-

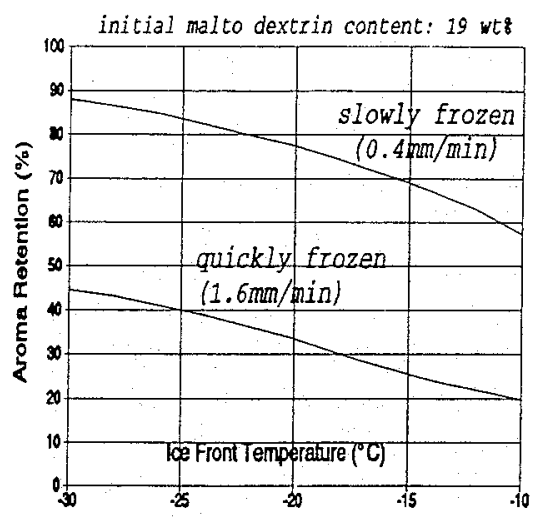

FIGURE 8. Effect of freezing rate on retention of n-alcohols in freeze drying of slabs of aqueous maltodextrin solution (Thijssen, 1975) condly, at decreasing temperatures the moisture concentration in the matrix phase is reduced according to the freezing curve (Figure 7) and because of this effect the selective diffusion principle is promoted in an overruling way. As a final result the aroma retention is improved at lower temperatures $\mathrm{T}_{f}$ (Figure 8). 4. A decrease of the slab thickness $L$ reduces the total drying time and the aroma retention will be improved. 5. A decrease of the pressure in the drying chamber reduces the vapour pressure $P_{w e}$ at the external slab surface, thus the driving force for drying is enlarged ( $\alpha$ decreases), the total drying time is reduced and consequently the aroma retention is enhanced. 
Processing Rules for Granules

Experiments have shown that the above processing rules are also applicable to freeze drying of a layer of granules (Thijssen, 1972; Rulkens, 1973). It was also observed that aroma retention decreased with decreasing particle size and increasing layer thickness. In both cases the resistance to vapour flow through the bed of granules is increased, consequently the sublimation rate decreases, the total drying time increases and the aroma retention decreases.

\section{DISPERSED AROMA COMPONENTS IN FREEZE DRYING}

The presence of small droplets inside freeze dried specimen have been observed microscopically (Flink and Gelj-Hansen, 1972). These droplets are either present in the original feed or are formed during the freezing process due to concentrating effects and to a decrease of the solubility of aroma components at lower temperatures. The retention of sparingly soluble aroma components in synthetic emulsions and in natural juices were studied by Massaldi and King (1974); mixtures of volatile components in supersaturated state were investigated by Kayaert $(1974,1975)$. The expermimental work so far was directed to dispersed aromas in freeze drying.

\section{Mechanisms for Aroma Losses}

Three main mechanisms by which aroma may be lost are schematically depicted in Figure 9:

- Diffusional losses of aroma components being homogeneously dissolved in the matrix phase. These losses occur during the first drying stage where selective 
diffusion has not yet come into action. This mechanism applies both for an undersaturated and a saturated matrix phase. In case of supersaturation the dispersed aroma droplets function as sources, maintaining the matrix phase at a saturated level.

- Losses by evaporation of aroma droplets. If the saturation level is exceeded droplets will be formed in the matrix. An important factor with respect to aroma retention is the location of droplets inside the matrix. If

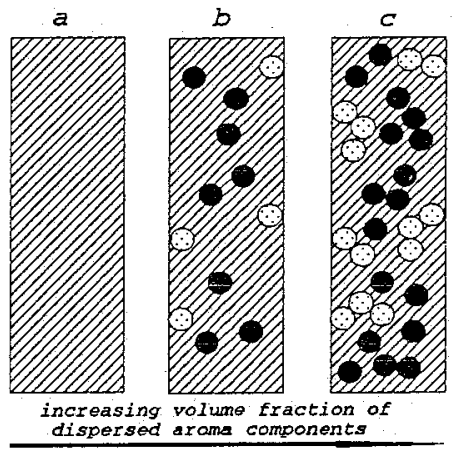
these droplets are 10cated adjacent to the ice crystals, they will evaporate by passing of the ice front. For synthetic emulsions it was found that a substantial amount of aroplets adhered to ice crystals; in case of natural juices the much smaller droplets have the opportunity to move away from the growing ice crystals by Brownian motion and are adhering to the cloud (Massaldi and King, 1974). The probability that an aroma droplet finds itself adjacent to an ice crystal increases with a larger droplet size and a smaller thickness $2 \delta$ of the matrix wall between the ice crystals. At increasing droplet concentration the probability of droplet aggregation increases. If now a surface 
droplet is lost, neighbouring droplets will be lost as well.

From the above considerations it can be concluded that the volumefraction of dispersed aroma in the matrix phase is an important parameter with respect to retention of dispersed aroma components (Kerkhof, 1977). In Figure 10 it can be seen that at increasing volume fraction the aroma retention decreases markedly. The experimental data obtained for 20 wt\% and 40 wto solids can be described

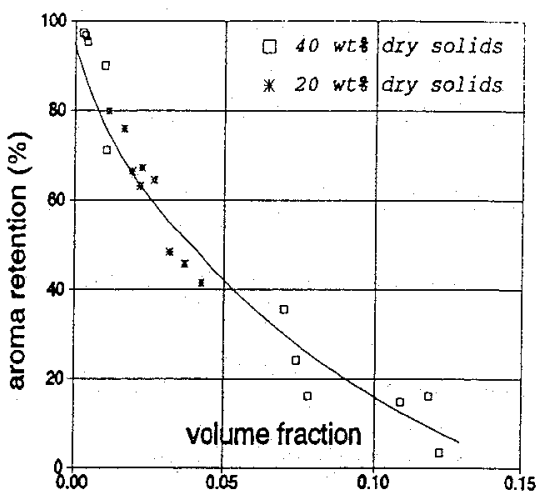
by a single curve.

\section{Processing Rules}

From the above considerations the effect of process variables on aroma retention can be formulated as follows:

1. Increasing the dissolved solids concentration (at constant aroma concentration) reduces the volume fraction of dispersed aroma in the matrix phase. Therefore the evaporation losses will be reduced. Moreover, the diffusional losses will also decrease for reasons mentioned earlier for homogeneously dissolved aroma components.

2. Decreasing the dispersed aroma concentration (at constant solids concentration) will lead to increasing aroma retention for similar reasons as mentioned above. 
3. Lower freezing rates lead to higher retention of homogeneously dissolved aroma components as mentioned earlier. Because larger and less ice crystals are formed, the wall thickness $2 \delta$ increases and the probability of aroma droplets to find themselves near the ice crystals decreases. Therefore the retention of dispersed aroma components will increase as well.

\section{CONCLUSIONS}

For spray drying and freeze drying the retention of aroma components during drying has been discussed extensively. For homogeneously dissolved aroma components quantitative physical/mathematical models, based on Thijssen's selective diffusion theory, are available. Unfortunately, the availability of the required physical properties (e.g. binary diffusion coefficients, activity coefficients, etc.) is poor. The losses of dispersed aroma components in super saturated systems during freeze drying is well understood qualitatively. It is observed that the volume fraction of the dispersed aroma phase plays a crucial role.

To reduce aroma losses during drying, many practical processing rules are discussed. However, obtaining the highest possible aroma retention does not mean obtaining the highest possible overall product quality. Process variables promoting aroma retention may have detrimental effects on other quality determining features of the product, e.g. bulk density, colour, artefacts due to chemical reactions, etc. As was pointed out earlier (Thijssen and Kerkhof, 1977), in spray drying a high initial dissolved solids concentration, leading to higher aroma retentions, will also cause easier thermal degradation of heat-labile components. In freeze drying at high initial dissolved solids 
concentrations a very dense product is obtained, which is unfavourable for good rehydration properties.

Experimental work on aroma retention in drying has been carried out on model systems, mostly carbohydrate solutions with one or more model aroma components added. It may be expected that the behaviour of real food systems will be very complicated, because thermally induced chemical reactions will also change the aroma profile in the product. Moreover, additional physical changes like crystallisation or other segregration reactions, e.g. during spray drying of droplets, will influence the selective diffusion phenomenon undoubtly.

NOTATION

A thermodynamic activity $(-/-)$

$A R$ fractional aroma retention $(-/-)$

B correlation parameter $(-/-)$

C molar concentration $\left(\mathrm{mol} / \mathrm{m}^{3}\right)$

$c_{p}$ specific heat $\left(\mathrm{J} / \mathrm{kg}{ }^{\circ} \mathrm{C}\right)$

d partial density of component $\left(\mathrm{kg} / \mathrm{m}^{3}\right)$

d diameter (m)

D diffusion coefficient $\left(\mathrm{m}^{2} / \mathrm{s}\right)$

D binary Maxwell-stefan diffusion coefficient $\left(\mathrm{m}^{2} / \mathrm{s}\right)$

E activation energy ( $\mathrm{J} / \mathrm{mol})$

$f$ binary friction coefficient $\left(\mathrm{Nm}^{2} \mathrm{~s} / \mathrm{mol}^{2}\right)$

f correlation parameter $(-/-)$

F correlation parameter $\left(\mathrm{m}^{2} / \mathrm{s}\right)$

Fo Fourier number $(-/-)$

$\mathrm{H}$ modified thermodynamic activity coefficient $\left(\mathrm{m}^{3} / \mathrm{kg}\right)$

$j^{s}$ mass flux with respect to solids velocity $\left(\mathrm{kg} / \mathrm{m}^{2} \mathrm{~s}\right)$

$k$ mass transfer coefficient in gas phase $(\mathrm{m} / \mathrm{s})$ 
I slab thickness in freeze drying ( $\mathrm{m}$ )

M molecular weight $(\mathrm{kg} / \mathrm{mol}$ )

$\mathrm{n}$ mass $f l u x$ in a fixed reference frame $\left(\mathrm{kg} / \mathrm{m}^{2} \mathrm{~s}\right)$

$\mathrm{N}$ molar flux in fixed reference frame $\left(\mathrm{mol} / \mathrm{m}^{2} \mathrm{~s}\right.$ )

$\mathrm{P}$ vapour pressure (Pa)

q heat flux $\left(\mathrm{w} / \mathrm{m}^{2}\right)$

$r$ space coordinate (m)

$R$ half thickness of slab, radius of cylinder or sphere (m)

$\mathrm{R}$ gas constant ( $\mathrm{J} / \mathrm{mol} \mathrm{K}$ )

sh Sherwood number

$t$ time (s)

$\mathrm{T}$ absolute temperature (K)

$v$ species velocity in a fixed reference frame ( $\mathrm{m} / \mathrm{s})$

WR fractional water retention $(-/-)$

$x$ relative distance $(-/-)$

$x$ molar fraction in condensed phase (mol/mol)

$y$ molar fraction in gas phase (mol/mol)

\section{Greek}

$\alpha$ heat transfer coefficient $\left(\mathrm{W} / \mathrm{m}^{2}{ }^{\circ} \mathrm{C}\right)$

$\alpha$ relative volatility $(-/-)$

$\alpha, \beta$ parameters defined in equations (39)-(41)

$\gamma$ thermodynamic activity coefficient $(-/-)$

$\delta$ half thickness of pore wall (m)

$\Delta \mathrm{H}$ enthalpy of vaporisation or enthalpy of subIimation ( $\mathrm{J} / \mathrm{kg}$ )

$\epsilon$ volume fraction of ice $\left(\mathrm{m}^{3} / \mathrm{m}^{3}\right)$

$\epsilon$ reduced flux $\left(\mathrm{m}^{2} / \mathrm{s}\right)$

$\theta$ temperature $\left({ }^{\circ} \mathrm{C}\right)$

$\lambda$ thermal conductivity $\left(w / m^{\circ} \mathrm{C}\right)$

$\mu$ chemical potential ( $\mathrm{J} / \mathrm{mol}$ )

$\nu$ geometry parameter $(-/-)$

$\rho$ mass concentration $\left(\mathrm{kg} / \mathrm{m}^{3}\right)$ 


$$
\begin{aligned}
& \tau \text { total drying time (s) } \\
& \phi \text { reduced time }\left(\mathrm{s} / \mathrm{m}^{2}\right) \\
& \omega \text { mass fraction }(\mathrm{kg} / \mathrm{kg})
\end{aligned}
$$

\section{Subscripts:}

a aroma component
c critical
$i \quad$ interface
$i, j$ components
is intersection point
K Knudsen
o initial value
p pore
s dissolved solids
w water
$\infty \quad$ bulk gas phase

\section{superscripts:}

gas phase
- pure component
s with respect to solids velocity
$\infty \quad$ at infinite dilution

REFERENCES

Bomben, J.L., Bruin, S., Thijssen, H.A.C., Merson, R.L., 1973, Aroma recovery and retention in concentration and drying of foods, Advan. Food Res., 20, 1-111

Carslaw, H.S., Jaeger, J.C., 1959, conduction of heat in solids, clarendon Press, oxford

Chandrasekaran, S.K., 1969, Volatiles retention during drying of food liquids, Ph.D.Thesis, University of California, Berkeley

Chandrasekaran, S.K., King, C.J., 1971, Retention of volatile flavor components during drying of fruit juices, Chem. Eng. Progr., Symp. Ser., $67(108), 122-30$ 
Chandrasekaran, S. K., King, C.J., 1972a, Multicomponent diffusion and vapor-liquid equilibriums of dilute organic components in aqueous sugar solutions, AIChE J., 18(3), 513-20

Chandrasekaran, S.K., King, C.J., 1972b, Volatiles retention during drying of food liquids, AIChE J., $18(3), 520-6$

Chirife, J.; Karel, M., 1973, Volatile retention during freeze drying of aqueous suspensions of cellulose and starch, J. Agr. Food Chem., $21(6), 936-9$

Chirife, J.; Karel, M.; Flink, J., 1974, Mechanisms of retention of volatile in freeze-dried food models. System PVP [poly(vinylpyrrolidone)]-propanol, J. Food Sci., $38(4), 671-4$

Chirife, J.; Karel, M., 1974, Contribution of adsorption to volatile retention in a freeze-dried food model containing PVP [poly(vinylpyrrolidinone)], J. Food Sci., $38(5), 768-71$

Chirife, J.; Karel, M., 1974, Volatile retention during freeze drying of protein solutions, Cryobiology, 11(2), 107-15

Coumans, W.J., 1987, Power law diffusion in drying processes, Ph.D.Thesis, Eindhoven University of Technology

Coumans, W.J., 1991, Measurement of aroma and water losses during drying, to be published soon (contribution IDS'90 at Prague).

Crank, J.,1975, The mathematics of diffusion, 2nd Edition, Clarendon Press, oxford

Etzel, M.R., King, C.J., 1980, Retention of volatile components during freeze drying of substances containing emulsified oils, J. Food Technol., 15(6), 577-88

Etzel, M.R., King, C.J., 1984, Loss of volatile trace organics during spray drying, Ind. Eng. Chem. Process Des. Dev., $23(4), 705-10$

Flink, J.M.; Gejl-Hansen, F., 1972, J.Agr.Food Chem., 20, p69

Flink, J.; Karel, M., 1970, Effects of process variables on retention of volatiles in freeze-drying, $J$. Food Sci., 35(4), 444-7 
Flink, J.; Karel, M., 1970, Retention of organic volatiles in freeze-dried solutions of carbohydrates, J. Agr. Food Chem., 18(2), 295-7

Flink, J.; Karel, M., 1972, Mechanisms of retention of organic volatiles in freeze-dried systems, J. Food Technol., $7(2), 199-211$

Flink, J., 1975, The retention of volatile components during freeze drying: a structurally based mechanism, Freeze Drying Adv. Food Technol., [Int. Course], Meeting Date 1973, 351-72. Edited by: Goldblith, S.A.; Rey, L.R.; Rothmayer, W.W.

Frey, D.D., King, C.J., 1982, Diffusion coefficients of acetates in aqueous sucrose solutions, J. Chem. Eng. Data, 27(4), 419-22

Frey, D.D., King, C.J., 1986a, Experimental and theoretical investigation of foam-spray drying.

1. Mathematical model for the drying of foams in the constant-rate period, Ind. Eng. Chem. Fundam., 25(4), $723-30$

Frey, D.D., King, C.J., 1986b, Experimental and theoretical investigation of foam-spray drying.

2. Experimental investigation of volatiles loss during foam-spray drying, Ind. Eng. Chem. Fundam., 25(4), $730-5$

Frey, D.D., King, C.J., 1986C, Effects of surfactants on mass transfer during spray drying, AIChE J., 32(3), $437-43$

Furuta, T., Okazaki, M., Toei, R., 1984, Flavor retention on drying of a single droplet under various drying conditions, Proc. Int. Drying Symp., 4 th, Volume 1, 336-42. Edited by: Toei, R., Mujumdar, A.S.

Furuta, T., Okazaki, M., Toei, R., 1985, Flavor retention on drying of a single droplet under various drying conditions, Drying $85,338-44$. Edited by: Toei, R., Mujumdar, A.S., Hemisphere: Washington, D. C.

Kayaert, G., 1974, Retention of volatile organic compounds during freeze-drying of model systems and shrimps, Agricultura (Louvain), 22(2), 101 pp.

Kayaert, G.; Tobback, P.; Maes, E.; Flink, J.; Karel, M., 1975, Retention of volatile organic compounds in a complex freeze-dried food gel, J. Food Technol., 10(1), $11-18$ 
Kerkhof, P.J.A.M., Schoeber, W.J.A.H., 1974, Theoretical modelling of the drying behaviour of droplets in spray dryers, pp.349-397, in Advances in Preconcentration and Dehydration of Foods, Appl.Science Publ.

Kerkhof;, P.J.A.M., Thijssen, H.A.C., 1974, Retention of aroma components in extractive drying of aqueous carbohydrate solutions, J. Food Technol., 9(4), 415-23

Kerkhof, P.J.A.M., 1974, Correlation between process variables and aroma loss in the drying of liquid foods, Proc. 4th Int.Congr.Food Sci.and Techn., Vol.4, pp.203220

Kerkhof, P.J.A.M., Thijssen, H.A.C., 1975, The effect of process conditions on aroma retention in drying liquid foods, Aroma Res., Proc.Int.symp., 167-92. Edited by: Maarse, H., Groenen, P.J., Cent. Agric. Publ. Doc.: Wageningen, Netherlands

Kerkhof, P.J.A.M., 1975, A Quantitative study of the Effect of Process Variables on the Retention of Volatile Trace Components in Drying, Ph.D.Thesis, Eindhoven University of Technology

Kerkhof, P.J.A.M., 1977, Preservation of aroma components during the drying of extracts, 8th collog. Sci. Int. Cafe, (Abidjan), 8, 235-48

Kerkhof, P.J.A.M., Thijssen, H.A.C., 1977, Quantitative study of the effects of process variables on aroma retention during the drying of liquid foods, AIChE Symp. Ser , 73(163), 33-46

Kieckbusch, T.G., King, C.J., 1977, Losses of volatiles in the nozzle zone during spray drying, Pac. Chem. Eng. Congr., 2(1), 216-21

Kieckbusch, T.G., King, C.J., 1979, An improved method of determining vapor-liquid equilibriums for dilute organics in aqueous solution, $J$. Chromatogr. Sci., $17(5), 273-6$

Kieckbusch, T.G., King, C.J., 1980, Volatiles loss during atomization in spray drying, AIChE J., 26(5), $718-25$

King, C.J., Chandrasekaran, S.K., 1973, Analysis of volatiles loss from food liquids during freeze-drying and evaporative drying as a ternary diffusion process, Progr. Refrig. Sci. Technol., Proc. Int. Congr. Refrig., 13th, Meeting Date 1971, volume 3, 649-56. Edited by: Pentzer, w. 
King, C.J., 1980, spray drying: volatiles retention and particle morphology, Food process Eng., [Proc. Int. Congr.], 2nd, Meeting Date 1979, 385-9. Edited by: Linko, P., Malkki, Y., Olkku, J., Appl. Science

king, c.J., 1984, control of food-quality factors in spray drying, Proc: Int. Drying Symp., 4th, volume 1 , 69-76. Edited by: Toei, R., Mujumdar, A.S.

King, C.J., Kieckbusch, T.G., Greenwald, C.G., 1984, Food-quality factors in spray drying., Advances in Drying, Vol.3., Hemisphere Publ Corp, Washington and London

King, C.J., 1990, Spray drying food liquids and the retention of volatiles, Chem. Eng. Prog., 86(6), 33-9. Also published in: Preconcentration and Drying of Food Materials, Editor Bruin, S., Elsevier Science Publishers, Amsterdam, 1988, pp 147-162

Kumazawa, E., Ido, K., Okazaki, M., Toei, R., 1984, vacuum drying of maltodextrin aqueous solution with ethanol in foamed state, Proc. 4th Int. Drying Symp., Volume 2, 480-6. Edited by: Toei, R., Mujumdar, A.S.

Liou, J.K., 1982, An approximate method for nonlinear diffusion applied to enzyme inactivation during drying, Ph.D.Thesis, Wageningen University of Agriculture

Luikov, A.V., 1968, Analytical heat diffusion theory, Academic Press, New York

Massaldi, H.A., King, C.J., 1973, simple technique to determine solubilities of sparingly soluble organics. Solubility and activity coefficients of d-limonene, butylbenzene, and n-hexyl acetate in water and sucrose solutions, J. Chem. Eng. Data, 18(4), 393-7.

Massaldi, H.A., King, C.J., 1974, Volatiles retention during freeze drying of synthetic emulsions, J. Food Sci., $39(3), 438-44$

Menting, L. C., Hoogstad, B., 1967, Volatiles retention during the drying of aqueous carbohydrate solutions, $J$. Food Sci., $32(1), 87-90$

Menting, L.C., 1969, Retention of Volatiles During the Air Drying of Aqueous Carbohydrate Solutions, Ph.D.Thesis, Eindhoven University of Technology 
Menting, L.C., Hoogstad, B., Thijssen, H.A.C., 1970, Aroma retention during the drying of liquid foods, J. Food Technol., 5(2), 127-39

Papadakis, S.E.,.King, C.J., 1988a, Air temperature and humidity profiles in spray drying. 1. Features predicted by the particle source in cell model, Ind. Eng. Chem. Res., 27(11), 2111-16

Papadakis, S.E., King, C.J., 1988b, Air temperature and humidity profiles in spray drying. 2. Experimental measurements, Ind. Eng. Chem. Res., 27(11), 2116-23

Rulkens, W.H., Thijssen, H.A.C., 1969, Numerical solution of diffusion equations with strongly variable diffusion coefficients. Calculation of flavor loss in drying food liquids, Trans. Inst. Chem. Eng., 47(9), (T292)-(T298) published in: Chem. Eng. (London), No. 233

Rulkens, w.H., Thijssen, H.A.C., 1972a, Retention of organic volatiles in spray-drying aqueous carbohydrate solutions, J. Food Technol., 7(1), 95-105

Rulkens, W.H., Thijssen, H.A.C., 1972b, Retention of volatile compounds in freeze-drying slabs of maltodextrin, J. Food Technol., 7(1), 79-93

Rulkens, W.H., 1973, Retention of Volatile Trace Components in Drying Ageous Carbohydrate Solutions, Ph.D.Thesis, Eindhoven University of Technology

Sandall, O.C., King, C.J., wilke C.R., 1967, The relationship between transport properties and rate of freeze drying of poultry meat, AIChE J. 13, 428-438

Sandall, O.C., 1968, Ph.D.Thesis, University of California, Berkeley

Schoeber, W.J.A.H., 1976, Regular Regimes in sorption Processes, Ph.D.Thesis, Eindhoven University of Techno$\operatorname{logy}$

Thijssen, H.A.C., 1965, Inaugural Address, Eindhoven University of Technology

Thijssen, H.A.C. and Rulkens, W.H., 1968, Retention of aromas in drying liquid foods, de Ingenieur, vol.80, p. $45-56$ 
Thijssen, H.A.C., 1970, Effect of process variables on aroma retention in drying coffee extract, 4th collog. Inst. Chim. Cafes Verts, Torrefies Leurs Deriv., Meeting Date 1969, 108-17. Assoc.Sci.Int.Cafe: Paris, Fr.

Thijssen, H.A.C., 1971, Flavor retention in drying preconcentrated food liquids, J. Appl. Chem. Biotechnol., $21(12), 372-7$

Thijssen, H.A.C., 1972a, Effect of process conditions in drying liquid foods on its aroma retention, Proc. 3rd Nord. Aroma Symp., 5-38. Helsinki, Finland.

Thijssen, H.A.C., 1972b, Prevention of aroma losses during drying of liquid foods, DECHEMA Monogr., 70, 353-66

Thijssen, H.A.C., 1974, Effect of process conditions in drying coffee extract and other liquid foods on aroma retention, Colloq. Int. Chim. Cafes, Volume Date 9 Jun $1973,6,222-33$

Thijssen, H.A.C., 1975, Effect of process conditions in freeze drying on retention of volatile components, pp.373-400, Chapter 23 in Freeze Drying and Advances in Food Technol., Meeting Date 1973, 373400, Edited by: Goldblith, S.A., Rey, L.R, Rothmayer, W.W.

Tsujimoto, S., Nishikawa, M., Furuta, T., Okazaki, M., Toei, R., 1984, Volatile loss in spray drying, Proc. 4 th Int. Drying Symp., Volume 1, 397-402. Edited by: Toei, R., Mujumdar, A.S.

Tsujimoto, S., Nishikawa, M., Furuta, T., Okazaki, M., Toei, R., 1985, Volatile loss in spray drying., DRYING'85, Hemisphere Publ Corp, Washington, p. 230-235

Tsujimoto, S., 1985, Analysis of Volatile Loss and its Prevention in Spray Drying, Ph.D.Thesis, Kyoto University

Verderber, P.A., King, C.J.,. 1991, Measurement of instantaneous rates of loss of volatile compounds during drying of drops, to be published in Drying Technology

Voilley, A.; Simatos, D.; Loncin, M., 1977, Retention of volatile trace components in freeze-drying model solutions, Lebensm.-Wiss. Technol., 10(5), 285-9 
Wesselingh, J.A., Krishna, R., 1990, Mass Transfer, Ellis Horwood Ltd, $243 \mathrm{p}$

Zakarian, J.A., King, C.J., 1982, Volatiles loss in the nozzle zone during spray drying of emulsions, Ind. Eng. Chem. Process Des. Dev., 21(1), 107-13 